\title{
Clinical Pharmacology of Opioids for Pain
}

\author{
Charles E. Inturrisi, Ph.D. \\ Department of Pharmacology, Weill Medical College of Cornell University, and the Pain and Palliative Care Service, Memorial \\ Sloan-Kettering Cancer Center, New York, New York, U.S.A.
}

\begin{abstract}
:
The pharmacological effects of the opioid analgesics are derived from their complex interactions with three opioid receptor types $(\mu, \delta$, and $\kappa$; morphine is an agonist at the $\mu$ opioid receptor). These receptors are found in the periphery, at presynaptic and postsynaptic sites in the spinal cord dorsal horn, and in the brain stem, thalamus, and cortex, in what constitutes the ascending pain transmission system, as well as structures that comprise a descending inhibitory system that modulates pain at the level of the spinal cord. The cellular effects of opioids include a decrease in presynaptic transmitter release, hyperpolarization of postsynaptic elements, and disinhibition. The endogenous opioid peptides are part of an endogenous pain modulatory system. A number of opioids are available for clinical use, including morphine, hydromorphone, levorphanol, oxymorphone, methadone, meperidine, oxycodone, and fentanyl, and their advantages and disadvantages for the management of pain are discussed. An understanding of the pharmacokinetic properties, as well as issues related to opioid rotation, tolerance, dependence, and addiction are essential aspects of the clinical pharmacology of opioids for pain.

Key Words: Analgesic—Endogenous opioid—Euphoria—Morphinelike agonist— Opioid receptor-Opioid rotation.

\section{Learning Objectives:}

After reading this article, physicians should be able to

1. understand the receptor sites and mechanisms of action of opioid analgesics;

2. recognize the pharmacokinetic and pharmacodynamic differences among opioids; and

3. distinguish the terms opioid tolerance, dependence, and addiction as they relate to the use of these drugs for the management of pain.
\end{abstract}

The use of opioid analgesic drugs is a commonly used method for the management of moderate to severe pain. During the past 20 years there has been a dramatic increase in our knowledge of the sites and mechanisms of action of opioids. ${ }^{1}$ The development of analytical methods has also been of great importance by facilitating pharmacokinetic studies of the disposition and fate of

Publication of this supplement was supported by an unrestricted educational grant from Purdue Pharma L.P.

Address correspondence and reprint requests to Dr. Charles E. Inturrisi, Department of Department of Pharmacology, Weill Medical College of Cornell University, and the Pain and Palliative Care Service, Memorial Sloan-Kettering Cancer Center, New York, NY, U.S.A. opioids in patients. These studies have begun to offer us a better understanding of some of the sources of interindividual variation in the response to opioids and to suggest ways to minimize some of their adverse effects. ${ }^{2,3}$ Although there are gaps in our knowledge of opioid pharmacology, the rational and appropriate use of these drugs is based on the knowledge of their pharmacologic properties derived from well-controlled clinical trials. ${ }^{4}$

Most of the clinical pharmacology of the opioids for the management of pain has been derived from studies of patients with pain due to cancer. ${ }^{5-7}$ More recent studies support the concept that the pharmacokinetic and pharmacodynamic properties of opioids established in cancer 
patients can be safely extended to noncancer patients with persistent pain. ${ }^{3}$ One of the major conclusions derived from the experience in managing cancer pain with opioids is that the abuse potential of these drugs is low when they are used to manage cancer pain in patients without a history of substance abuse. ${ }^{2-4}$ The extent to which this observation can be extended to the noncancer pain populations is beyond the scope of this review, but is well covered elsewhere in this supplement.

\section{OPIOID ANALGESICS}

The opioid analgesics are characterized by their important pharmacologic differences, which are derived from their complex interactions with three opioid receptor types $(\mu, \delta$, and $\kappa){ }^{1}$ These opioid receptors belong to the $\mathrm{G}$ protein-coupled receptor family and they signal via a second messenger (cyclic AMP) or an ion channel $\left(\mathrm{K}^{+}\right){ }^{1}$ Alterations in the levels of cyclic AMP during long-term morphine treatment are associated with a number of cellular changes, including the development of tolerance and physical dependence. ${ }^{8}$ Recently, molecular genetic approaches have used gene targeting (knockout) technology to disrupt the gene that codes for each of the three opioid receptors. ${ }^{9}$ Mice that lack the $\mu$ receptor (MOR-deficient mice) do not respond to morphine with analgesia, respiratory depression, constipation, physical dependence, reward behaviors, or immunosuppression. ${ }^{9}$ These results confirm and extend previous pharmacologic and receptor-binding studies and demonstrate that the $\mu$ receptor mediates the analgesic and adverse effects of morphine. Pharmacologic evaluation of the effects of the microinjection of morphine and other opioids has been combined with anatomic characterization of the distribution of opioid receptors to provide insight into the sites of action of morphine and other clinically used $\mu$ opioids. Thus, $\mu$ opioid receptors are found in the periphery (following inflammation), at pre and postsynaptic sites in the spinal cord dorsal horn and in the brain stem, thalamus and cortex, in what constitutes the ascending pain transmission system. ${ }^{10}$ In addition, $\mu$ opioid receptors is found in the midbrain periaqueductal grey, the nucleus raphe magnus, and the rostral ventral medulla where they comprise a descending inhibitory system that modulates spinal cord pain transmission. ${ }^{10}$ At a cellular level, opioids decrease calcium ion entry resulting in a decrease in presynaptic neurotransmitter release (e.g., substance $\mathrm{P}$ release from primary afferents in the spinal cord dorsal horn). They also enhance potassium ion efflux resulting in the hyperpolarization of postsynaptic neurons and a decrease in synaptic transmission. A third mode of opioid action is the inhibition of GABAergic transmission in a local circuit (e.g., in the brain stem, where GABA acts to inhibit a pain-inhibitory neuron). This disinhibitory action of the opioid has the net effect of exciting a descending inhibitory circuit.

The opioid receptors are part of an endogenous opioid system that includes a large number of endogenous opioid peptide ligands. Based on cloning, three distinct families of classic opioid peptides - the enkephalins, endorphins, and dynorphins-have been identified. ${ }^{1}$ The physiologic roles of the endogenous opioid peptides are not completely understood. They appear to function as neurotransmitters, neuromodulators, and in some cases, as neurohormones. They play a role in some forms of stress-induced analgesia and in the analgesia produced by electrical stimulation of discrete brain areas such as the periaqueductal gray. ${ }^{1,10}$

Animal studies suggest that the reinforcing and rewarding properties of opioids (e.g., euphoria) that are associated with opioid abuse involve the mesolimbic dopamine system and appear to be distinct from those supraspinal systems involved in the production of analgesia and physical dependence. ${ }^{1}$

The morphinelike agonist drugs represent one end of a spectrum; they bind predominately to the $\mu$ opioid receptor and produce analgesia. The opioid antagonists represent the other end of the spectrum. Thus, naloxone, an opioid antagonist, binds to each of the three opioid receptor types. Its highest affinity is for the $\mu$ opioid receptor and it can block or reverse the effects of morphinelike agonists. Between these two groups are the mixed agonist-antagonist drugs that, depending on the patient circumstances, can demonstrate agonist activity at the $\kappa$ receptor or antagonist activity at the $\mu$ opioid receptors.

\section{Morphinelike agonists}

Morphine is the prototype and standard of comparison for opioid analgesics. The morphinelike agonists (Table 1) share with morphine a similar profile of pharmacodynamic effects, both desirable and undesirable. However, they differ in factors critical in dosage selection (i.e., relative analgesic potency and oral to parenteral $[\mathrm{im} / \mathrm{po}]$ analgesic potency). They also differ in pharmacokinetics (e.g., elimination half-life) and biotransformation to pharmacologically active metabolites. ${ }^{2,3}$ These latter characteristics are of particular importance when opioid administration is continued beyond 1 or 2 days. Much of this information is summarized in Table 1 and detailed in references 2 through 7 .

\section{Morphine}

Morphine's oral bioavailability varies from 35 to $75 \%$. Its plasma half-life (2-3.5 hours) is somewhat shorter than its duration of analgesia (4-6 hours), which limits 
TABLE 1. Opioid analgesics commonly used for severe pain

\begin{tabular}{|c|c|c|c|c|c|}
\hline Name & $\begin{array}{l}\text { Equianalgesic } \\
\text { im dose* }\end{array}$ & $\mathrm{Im} /$ Po potency & $\begin{array}{l}\text { Starting oral dose } \\
\text { range }(\mathrm{mg})\end{array}$ & Comments & Precautions \\
\hline \multicolumn{6}{|l|}{ Morphinelike agonists } \\
\hline Morphine & 10 & 6 & $30-60 \dagger$ & $\begin{array}{l}\text { Standard of comparison for } \\
\text { opioid analgesics; } \\
\text { sustained-release preparations } \\
\text { (MS Contin, Oramorph SR } \\
\text { and Kadian) }\end{array}$ & $\begin{array}{l}\text { Lower doses for aged patients; } \\
\text { impaired ventilation; bronchial } \\
\text { asthma; increased intracranial } \\
\text { pressure; liver failure }\end{array}$ \\
\hline Hydromorphone (Dilaudid) & 1.5 & 5 & $4-8$ & $\begin{array}{l}\text { Slightly shorter acting; HP im } \\
\text { dosage form for tolerant } \\
\text { patients }\end{array}$ & Like morphine \\
\hline Methadone (Dolophine) & 10 & 2 & $10-20$ & $\begin{array}{l}\text { Good oral potency; long plasma } \\
\text { half-life }\end{array}$ & $\begin{array}{l}\text { Like morphine; may accumulate } \\
\text { with repetitive dosing, causing } \\
\text { excessive sedation }\end{array}$ \\
\hline Levorphanol (Levo-Dromoran) & 2 & 2 & $2-4$ & Like methadone & Like methadone \\
\hline Oxymorphone (Numorphan) & 1 & See comments & See comments & $\begin{array}{l}\text { Not available orally; available as } \\
\text { a rectal suppository }\end{array}$ & Like im morphine \\
\hline Oxycodone & 20 & - & $15-30$ & $\begin{array}{l}\text { Immediate-release (Roxicodone } \\
\text { and Oxy IR) and } \\
\text { sustained-release (Oxycontin) } \\
\text { forms; also lower doses in } \\
\text { combination with nonopioids } \\
\text { for less severe pain }\end{array}$ & Like morphine \\
\hline Meperidine (Demerol) & 75 & 4 & Not recommended & $\begin{array}{l}\text { Slightly shorter acting; used } \\
\text { orally for less severe pain }\end{array}$ & $\begin{array}{l}\text { Normeperidine (toxic metabolite) } \\
\text { accumulates with repetitive } \\
\text { dosing causing CNS } \\
\text { excitation; not for patients } \\
\text { with impaired renal function } \\
\text { or receiving monoamine } \\
\text { oxidase inhibitors } \$\end{array}$ \\
\hline Codeine & 130 & 1.5 & See comments & Used orally for less severe pain & Like morphine \\
\hline Fentanyl & 0.1 & - & - & $\begin{array}{l}\text { Transdermal fentanyl } \\
\text { (Duragesic); also oral } \\
\text { transmucosal fentanyl citrate } \\
\text { for breakthrough pain }\end{array}$ & $\begin{array}{l}\text { Transdermal creates skin } \\
\text { reservior of drug; 12-hour } \\
\text { delay in onset and offset; } \\
\text { fever increases absorption }\end{array}$ \\
\hline \multicolumn{6}{|l|}{ Mixed agonist-antagonists } \\
\hline Pentazocine (Talwin) & 60 & 3 & See comments & $\begin{array}{l}\text { Used orally for less severe pain; } \\
\text { mixed agonist-antagonist }\end{array}$ & $\begin{array}{l}\text { May cause psychotomimetic } \\
\text { effects; may precipitate } \\
\text { withdrawal in opioid } \\
\text { dependent patients; not for } \\
\text { myocardial infarction }\end{array}$ \\
\hline Nalbuphine (Nubain) & 10 & See comments & See comments & $\begin{array}{l}\text { Not available orally; like im } \\
\text { pentazocine but not } \\
\text { "scheduled" }\end{array}$ & $\begin{array}{l}\text { Incidence of psychotomimetic } \\
\text { effects lower than with } \\
\text { pentazocine }\end{array}$ \\
\hline Butorphanol (Stadol) & 2 & See comments & See comments & $\begin{array}{l}\text { Not available orally like im } \\
\text { nalbuphine }\end{array}$ & Like nalbuphine \\
\hline \multicolumn{6}{|l|}{ Partial agonists } \\
\hline Buprenorphine (Buprenex) & 0.4 & See comments & See comments & $\begin{array}{l}\text { Not available orally; sublingual } \\
\text { preparation not yet in U.S.; } \\
\text { does not produce } \\
\text { psychotomimetic effects }\end{array}$ & $\begin{array}{l}\text { May precipitate withdrawal in } \\
\text { opioid-dependent patients; not } \\
\text { readily reversed by naloxone; } \\
\text { avoid in labor }\end{array}$ \\
\hline
\end{tabular}

For these equianalgesic im doses (also see comments) the time of peak analgesia in nontolerant patients ranges from one-half to one hour and the duration from four to six hours. The peak analgesic effect is delayed and the duration prolonged after oral administration. Oramorph SR and Roxicodone are manufactured by Roxane Laboratories (Columbus, OH); Kadian, by Faulding USA (Elizabeth, NJ); Oxycontin; by Purdue Pharma LP (Norwalk, CT); Dilaudid, by Knoll Pharmaceuticals (Mt. Olive, NJ); Dolophine, by Eli Lilly and Co. (Indianapolis, IN), Nomorphan, by Endo Laboratories (Chadds Ford, PA); Demerol and Talwin, by Sanofi Winthrop Pharmaceuticals (New York, NY); Duragesic, by Janssen Pharmaceuticals (Titusville, NJ); Nubain, by Du Pont Merck Pharmaceuticals (Wilmington, DE); Stadol, by Bristol-Myers Squibb (Princeton, NJ); and Buprenex, by Reckitt \& Colman (Richmond, VA).

*These doses are recommended starting im doses, from which the optimal dose for each patient is determined by titration and the maximal dose limited by adverse effects. For single intravenous bolus doses use half the im dose.

$\dagger$ A value of 3 is used when calculating an oral dosage regimen of every 4 hours around-the-clock.

$\$$ Irritating to tissues on repeated administration.

im, intramuscular; po, oral.

accumulation. During repetitive administration, its pharmacokinetics remain linear and there does not appear to be autoinduction of biotransformation even following large chronic doses. ${ }^{2}$ These pharmacokinetic properties contribute to the safe use of morphine. Morphine-6-glucuronide (M-6-G) is an active metabolite of morphine that appears to contribute to the analgesic activity of morphine. ${ }^{11}$ In addition, animal studies indicate that M-6-G produces pharma- cologic actions at what appear to be opioid receptors derived from splice variants of the cloned $\mu$ receptor where morphine is inactive. ${ }^{12} \mathrm{M}-6-\mathrm{G}$ is eliminated by the kidney and will accumulate relative to morphine in patients with renal insufficiency. ${ }^{13-15}$ The degree to which this accumulation of M-6-G contributes to the incidence and severity of adverse effects experienced by these patients has not been conclusively demonstrated. ${ }^{14,15}$ In a survey that measured 
steady-state morphine and M-6-G levels and adverse effects in 109 cancer patients, the presence of myoclonus or cognitive impairment was not associated with M-6-G accumulation. ${ }^{14}$ For a subset of the 20 patients with the highest M-6-G levels (>2,000 $\mu \mathrm{g} / \mathrm{ml})$, the $\mathrm{M}-6-\mathrm{G}$ level and concurrent organ failure was associated with the most severe toxicity (respiratory depression and/or obtundation). ${ }^{14}$ It is appropriate to consider an alternate opioid for a patient receiving morphine who experiences a decrease in renal function and a concomitant increase in undesirable effects. Morphine-3-glucuronide (M-3-G), the predominate metabolite of morphine in humans, is devoid of opioid activity but has excitatory effects in animals after direct injection into the central nervous system (CNS). This has led to the suggestion that M-3-G may be responsible for the neuroexcitatory effects sometimes seen with large chronic morphine dosing. ${ }^{16}$ This speculation awaits definitive studies in patients receiving morphine.

Based on single-dose studies in patients with acute or chronic pain, the relative potency of intramuscular to oral morphine is 1:6. However, with repeated administration, when patients are dosed on a regular schedule (around-the-clock), the im:po ratio is reduced to $1: 2$ or 1:3. Thus, for patients with acute pain who are being titrated using a prn schedule, the 1:6 ratio should be used initially with a lower ratio expected, if dosing continues and a steady state develops.

The delayed-release morphine preparations provide analgesia with duration of 8 to 12 hours (MS-Contin; Roxanol-SR; Roxane Laboratories, Columbus, $\mathrm{OH}$, U.S.A.) or 24 hours (Kadian; Faulding USA, Elizabeth, NJ, U.S.A.) and allow the cancer patient a greater freedom from repetitive dosing especially during the night. These preparations appear to be safe and efficacious. Patients should be initially titrated on immediate release morphine and once stabilized converted to the delayedrelease preparation according to either an 8-hour or a 12-hour dosing schedule. To manage acute "breakthrough" pain, "rescue" medication (immediate-release morphine) should be made available to the patient receiving delayed-release preparations.

Table 1 lists other morphinelike agonists that may be substituted for morphine. An alternative opioid to morphine may be selected based on the need with a particular patient to overcome an adverse effect of morphine (e.g., vomiting or sedation). Other reasons include the patient's favorable prior experience with another opioid or even local availability of other morphinelike opioids. It must be emphasized that there is no evidence to suggest that any opioid has greater analgesic efficacy than morphine.

\section{Hydromorphone}

Hydromorphone is a short half-life opioid used as an alternate to morphine by the oral and parenteral routes. It is more soluble than morphine and available in a concentrated-dosage form at $10 \mathrm{mg} / \mathrm{ml}$. This preparation is intended for parenteral administration to the opioid tolerant patient and/or the cachectic patient, where the volume of the opioid solution to be injected must be limited. In this regard hydromorphone serves the same role in cancer pain management in the United States as does heroin in those countries where it is available.

\section{Levorphanol}

Levorphanol, a long half-life opioid (Table 2), is also a useful alternative to morphine but it must be used cautiously to prevent accumulation. For patients who are unable to tolerate morphine and methadone, levorphanol represents a useful medication with a good oral to parenteral potency ratio of $1: 2$.

\section{Oxymorphone}

Oxymorphone, a congener of morphine, has had a limited but important role in the management of pain. It is currently most widely used in suppository form, infrequently used parenterally on a long-term basis, and is not available orally.

\section{Methadone}

Methadone's oral bioavailability is $85 \%$, and single-dose studies have estimated an oral to parenteral potency ratio of 1:2. Its plasma half-life averages 24 hours (Table 2 ) but may range from 13 to 50 hours, whereas the duration of analgesia is often only 4 to 8 hours. ${ }^{2,3}$ Repetitive analgesic doses of methadone lead to drug accumulation because of the discrepancy between its plasma half-life and the duration of analgesia. Sedation, confusion, and even death can occur when patients are not carefully monitored and the

TABLE 2. Plasma half-life values for opioids and their active metabolites

\begin{tabular}{lc}
\hline & Plasma half-life (hours) \\
\hline Short half-life opioids & $2-3.5$ \\
Morphine & 2 \\
Morphine-6-glucuronide & $2-3$ \\
Hydromorphone & $2-3$ \\
Oxycodone & 3.7 \\
Fentanyl & 3 \\
Codeine & $3-4$ \\
Meperidine & $2-3$ \\
Pentazocine & 5 \\
Nalbuphine & $2.5-3.5$ \\
Butorphanol & $3-5$ \\
Buprenorphine & \\
Long half-life opioids & 24 \\
Methadone & $12-16$ \\
Levorphanol & 12 \\
Propoxyphene & $30-40$ \\
Norpropoxyphene & $14-21$ \\
Normeperidine &
\end{tabular}


dosage is not adjusted as needed during the accumulation period, which can last from 5 to 10 days. ${ }^{2,3}$ However, it is a useful alternative to morphine but requires greater sophistication in its clinical use as compared with morphine. Initial doses should be titrated carefully and as the needed (prn) mode of dosing used during the titration period. Ripamonti et al. ${ }^{17}$ reported a prospective study of 38 consecutive cancer patients who were switched from morphine to oral methadone and titrated to effect so that the equianalgesic dose ratio (morphine/methadone) could be estimated. The dose ratio increased as a function of the prior morphine dose so that no single dose ratio was appropriate for both opioid-naive patients and patients who were receiving long-term morphine therapy at the time they were switched to methadone. The data indicate that those patients who were receiving the highest doses of morphine were relatively more sensitive to the analgesic effects of methadone, (i.e., they had the highest dose ratio). This unidirectional variability in the dose ratio may reflect incomplete cross-tolerance between morphine and methadone and complicates the calculation of an equianalgesic dose when switching to methadone. ${ }^{18}$

The dosage form of methadone that is used clinically in most countries, including the United States, is a racemic mixture of equal amounts of the l-isomer, an opioid, and the d-isomer, which has only weak opioid activity. ${ }^{19,20,21}$ However, both the 1 and $d$ isomers of methadone bind to the NMDA receptor, and the d-isomer has functional NMDA receptor antagonist activity in animals, including antihyperalgesic activity and the ability to prevent the development of morphine tolerance. ${ }^{19,20,22}$ Some of the implications of these properties will be discussed.

\section{NMDA receptor antagonists and pain management}

A variety of compounds have been found to possess NMDA receptor antagonist activity in binding studies and/or in animal models. These include some opioids (methadone, meperidine, ketobemidone, and dextropropoxyphene) and a diverse group of other compounds (e.g., racemic ketamine and its isomers, dextromethorphan and memantine). ${ }^{19,20,22,23}$ These compounds have antihyperalgesic and antiallodynic activity in animal models of painful peripheral neuropathy ${ }^{23}$ and in other models that also involve central sensitization. ${ }^{21}$ The clinical usefulness of some of these compounds, (e.g., ketamine) as single-entity analgesics in neuropathic pain has been limited by adverse effects in most patients. ${ }^{24}$ Dextromethorphan is effective in painful diabetic neuropathy in patients who can tolerate high doses. ${ }^{24}$ Preclinical studies have also revealed that these same NMDA receptor antagonists can prevent or reverse the development of morphine tolerance. ${ }^{22}$ Taken together these observations suggest that the combination of an opioid plus an NMDA receptor antagonist should be of particular value in pain states where the potency of the opioid has been reduced as a result of hyperalgesia and/or morphine tolerance. ${ }^{18,20}$ This new therapeutic strategy has led to the development of a morphinedextromethorphan combination (Morphi-Dex), which is currently undergoing clinical trials. ${ }^{27}$ It may be expected that other combinations will also be evaluated. In this context, racemic methadone represents a natural combination of an opioid and isomers with NMDA receptor antagonist activity. Although subject to much speculation, the relative contributions of its opioid and NMDA receptor antagonist components have not been evaluated in patients with pain. A number of favorable therapeutic consequences could result from this type of combination and the initial clinical studies of Morphi-Dex have provided some insights. In single-dose studies additive or synergistic analgesic effects are seen, so that a lower dose of morphine can be used with the combination. ${ }^{25}$ The combination does not result in an increase in respiratory depression or abuse liability. ${ }^{26}$ It remains to be determined whether the combination also results in a reduction in adverse effects or the prevention or reversal of morphine tolerance. ${ }^{27}$ Importantly, we also need to learn whether the combination provides an increase in maximal efficacy that extends to conditions that are less responsive to opioids, such as neuropathic pain.

\section{Meperidine}

Studies of meperidine in cancer patients have demonstrated that repetitive dosing can lead to accumulation of its toxic metabolite, normeperidine, resulting in CNS hyperexcitability. ${ }^{2}$ This is initially characterized by subtle mood effects (e.g., anxiety), followed by tremors, multifocal myoclonus, and occasionally by seizures. This CNS hyperexcitability occurs commonly in patients with renal disease but it can occur following repeated administration in patients with normal renal function. ${ }^{2}$

\section{Oxycodone}

Oxycodone is available both as an immediate-release and a continuous-release (8-12-hour duration) preparation (Oxycontin; Purdue Pharma LP, Norwalk, CT, U.S.A.) and these dosage forms can be used for moderate to severe pain. However, lower doses (e.g., $5 \mathrm{mg}$ ) in combination with nonopioids (aspirin, acetaminophen) are frequently used for mild to moderate pain. The fixed dose oxycodone combinations should not be used chronically in large doses for more severe pain because of the risk of dose-related toxicity from the nonopioid ingredients. 


\section{Fentanyl}

Fentanyl is approximately 80 to 100 times as potent as morphine. ${ }^{1,4}$ It is a highly lipophilic drug with a shorter duration of action than parenteral morphine. Fentanyl is used for the management of postoperative pain by the intravenous and epidural routes of administration, a transdermal patch device is used for chronic pain requiring opioid analgesia, and a transmucosal dosage form is used for breakthrough cancer pain.

\section{Agonist-antagonist analgesics}

The mixed agonist-antagonist analgesics (Table 1) include pentazocine, butorphanol, and nalbuphine. They produce analgesia in the nontolerant patient but may precipitate withdrawal in patients who are tolerant and dependent on morphinelike drugs. Therefore, when used for chronic pain they should be tried before repeated administration of a morphinelike agonist drug. There is a ceiling effect on the ability of the mixed agonistantagonists to produce respiratory depression and they have a significantly lower abuse liability than the morphinelike drugs. In therapeutic doses, they may produce certain self-limiting psychotomimetic effects in some patients, and pentazocine is the most common drug associated with these effects. ${ }^{2,3}$ These drugs play a very limited role in the management of chronic pain because the incidence and severity of the psychotomimetic effects increase with dose escalation, ${ }^{2,3}$ and because they are not available in convenient oral dosage forms. Thus, nalbuphine is only available for parenteral use and the oral preparation of pentazocine is marketed in combination with naloxone. Butorphanol is available for both parenteral and intranasal use. Recent single-dose studies indicate that women may derive more pain relief than males from $\kappa$ opioid analgesics ${ }^{28,29}$ and these observations may stimulate the development of $\kappa$ opioids that can be administered by routes (oral, transdermal) that are appropriate for the management of persistent pain.

\section{Partial-agonist analgesics}

The partial agonist buprenorphine (Table 1) has less abuse liability than the morphinelike drugs, but like the mixed agonist-antagonists, it may also precipitate withdrawal in patients who have received repeated doses of a morphinelike agonist and developed physical dependence. However, it does not produce the psychotomimetic effects seen with the mixed agonist-antagonists and is available in both a sublingual and parenteral form. Only the latter dosage form is currently available in the United States. Buprenorphine's respiratory depressant effects are reversed only by relatively large doses of naloxone. ${ }^{30}$ It has been studied in cancer patients with pain and is useful for moderate to severe pain requiring an opioid analgesic. However, it should be used before the morphinelike agonists are introduced. ${ }^{2}$

\section{OPIOID PHARMACOKINETICS}

As noted previously, the opioids differ significantly in one measure of drug elimination: the plasma half-life value (Table 2). Thus, while morphine and hydromorphone are short half-life opioids that on repeated dosing reach steady-state in 10 to 12 hours, levorphanol and methadone are long half-life opioids that on the average may require 70 to 120 hours, respectively, to achieve steady-state. During dose titration the maximal (peak) effects produced by a change dose of a short half-life opioid will appear relatively quickly, while the peak effects resulting from a change in the dose of a long halflife opioid will be achieved after a longer accumulation period. For example, a patient who reports adequate pain relief following the initial doses of methadone may experience excessive sedation if this dosage is fixed and not modified as required during the accumulation period of 5 to 10 days.

Also, note that because the active (toxic) metabolites, normeperidine and norpropoxyphene, have much longer plasma half-life values than their corresponding parent drugs (meperidine and propoxyphene), administration of the parent on a schedule designed to produce continued pain relief results in accumulation of the metabolite. ${ }^{2,3}$ Opioid pharmacokinetics are altered by certain drug and/or disease interactions. ${ }^{2}$

\section{ROUTE OF ADMINISTRATION}

Opioids are available in dosage forms for use by a number of routes of administration, including oral, transdermal, intramuscular, intravenous (bolus, continuous infusion and patient controlled), subcutaneous infusion, rectal, epidural, intrathecal, intranasal, and transmucosal. The rationale for each route of administration, dosage form, and dose range is detailed in the American Pain Society guidelines. ${ }^{4}$

\section{Opioid rotation}

Opioid rotation (OR) involves switching the opioid a patient is receiving to another opioid with the objective of reducing limiting adverse effects and/or increasing analgesia. Surveys as well as a great deal of anecdotal evidence suggests that OR can 'open the therapeutic window' by reducing limiting adverse effects. ${ }^{31}$ The basis for the utility of OR is not well understood. For some opioids, OR may eliminate the adverse effects produced by the accumulation of toxic metabolites. ${ }^{31}$ We suspect that interindividual differences in analgesic responsiveness, not sensitivity to adverse effects, plays a major role 
in the advantage that one opioid appears to have over another in a particular patient. However, we have only begun to understand some of the patient factors that might predispose one individual to have a greater likelihood of experiencing an adverse effect from one opioid than from another. ${ }^{33}$ Finally, as discussed previously (Methadone), cross-tolerance is not complete among the opioids so that the calculation of an equianalgesic dose is much more complicated in patients who have received increasing doses of an opioid. ${ }^{2,3}$ Anderson et al. ${ }^{32}$ discuss these issues and provide some useful recommendations for safely utilizing OR. Also, when using the values in Table 1 for OR it becomes important to recognize that the equianalgesic dose estimates are based on the singledose studies and represent a useful reference point for the initiation of dose titration. Furthermore, since they do not take into account incomplete cross-tolerance, they cannot be used to calculate an equianalgesic dose for every patient with additional considerations. ${ }^{32}$

\section{SCHEDULED OPIOID ADMINISTRATION}

The schedule of opioid administration should be individualized for each patient. In general, patients with persistent pain should receive opioids on a regular schedule once the patient's dosage has been established by titration using an as-needed (prn) schedule. This approach is especially important when the dose titration involves a long half-life opioid such as methadone or levorphanol, as discussed previously. A regular around-the-clock schedule of opioid administration can prevent the recurrence of severe pain and may allow for a reduction in the total opioid required per day. For some patients a prn order for a supplemental opioid dose (rescue) between the regularly scheduled doses may be required to provide adequate pain relief.

\section{DRUG COMBINATIONS THAT ENHANCE ANALGESIA}

Drug combinations can provide additive analgesia, may reduce adverse effects, and can reduce the rate of escalation of the opioid portion of the combination. ${ }^{2-5}$ Several combinations produce additive analgesic effects, including an opioid plus one of the following: a nonopioid analgesic (acetaminophen, a salicylate or an NSAID of either the mixed COX-1 and COX-2 or COX-2 inhibitor type), caffeine, hydroxyzine (an antihistamine), methotrimeprazine (a phenothiazine), or dextroamphetamine (a stimulant). Other adjuvant analgesics that are commonly used with opioids are the tricyclic antidepressants (amitriptyline, imipramine, nortriptyline, and desipramine) and the anticonvulsants (gabapentin, phenytoin, carbamazepine, sodium valproate, and clonazepam). ${ }^{2-5}$

\section{ADVERSE EFFECTS OF OPIOIDS}

There are a number of side effects associated with the use of opioid analgesics that can, depending on the circumstances, be categorized as desirable or undesirable effects. $^{2-5}$ The mechanisms that underlie these various adverse effects are only partly understood and appear to depend on a number of factors including age, extent of disease and organ dysfunction, concurrent administration of certain drugs, prior opioid exposure, and the route of drug administration. ${ }^{2-5}$ The most common adverse effects are sedation, nausea and vomiting, constipation, and respiratory depression. But there are other adverse effects including confusion, hallucinations, nightmares, urinary retention, multifocal myoclonus, dizziness, dysphoria, and hyperalgesia that have been reported by patients receiving these drugs. ${ }^{34}$

\section{Respiratory depression}

Respiratory depression is potentially the most serious adverse-effect. The morphinelike agonists act on brainstem respiratory centers to produce, as a function of dose, increasing respiratory depression to the point of apnea. In humans, death due to overdose of a morphinelike agonist is nearly always due to respiratory arrest. Therapeutic doses of morphine may depress all phases of respiratory activity (rate, minute volume, and tidal exchange). However, as $\mathrm{CO}_{2}$ accumulates it stimulates central chemoreceptors, resulting in a compensatory increase in respiratory rate, which masks the degree of respiratory depression. At equianalgesic doses, the morphinelike agonists produce an equivalent degree of respiratory depression. For these reasons individuals with impaired respiratory function or bronchial asthma are at greater risk of experiencing clinically significant respiratory depression in response to usual doses of these drugs. Respiratory depression and $\mathrm{CO}_{2}$ retention result in cerebral vasodilation and an increase in cerebrospinal fluid pressure unless $\mathrm{PCO}_{2}$ is maintained at normal levels by artificial ventilation. When respiratory depression occurs, it is usually in opioid-naive patients following acute administration of an opioid and is associated with other signs of CNS depression including sedation and mental clouding. Tolerance develops rapidly to this effect with repeated drug administration, allowing the opioid analgesics to be used in the management of chronic pain without significant risk of respiratory depression. If respiratory depression occurs, it can be reversed by the administration of the specific opioid antagonist naloxone. In patients receiving long-term opioid therapy who 
develop respiratory depression, naloxone diluted 1:10 should be titrated carefully to prevent the precipitation of severe withdrawal symptoms while reversing the respiratory depression. An endotracheal tube should be placed in the comatose patient before administering naloxone to prevent aspiration-associated respiratory compromise with excessive salivation and bronchial spasm. In patients receiving long-term meperidine therapy, naloxone may precipitate seizures by blocking the depressant action of meperidine and allowing the convulsant activity of the active metabolite, normeperidine, to manifest. ${ }^{2}$ If naloxone is to be used in this situation, diluted doses slowly titrated with appropriate seizure precautions are advised.

The mixed agonist-antagonists and the partial agonist (buprenorphine) appear to differ in the dose-response characteristics of their respiratory depression curves from that of the morphinelike drugs, so that while therapeutic doses of pentazocine produce respiratory depression equivalent to that of morphine, increasing the dose does not ordinarily produce a proportional increase in respiratory depression. Whether this apparent ceiling to respiratory depression offers any clinical advantage remains to be determined. Also, the clinical symptoms of a large overdose of these drugs, with particular respect to respiratory depression, have not been well defined. ${ }^{30}$

\section{Nausea and vomiting}

The opioid analgesics produce nausea and vomiting by an action on the medullary chemoreceptor trigger zone. The incidence of nausea and vomiting is markedly increased in ambulatory patients suggesting that these drugs also alter vestibular sensitivity. The ability of opioid analgesics to produce nausea and vomiting appears to vary with drug and patient so that some advantage may result from opioid rotation. Alternately, an antiemetic may be used in combination with the opioid. For some patients initiating treatment by the parenteral route and then switching to the oral route may reduce the emetic symptoms. ${ }^{3}$

\section{Sedation}

The opioid analgesics produce sedation and drowsiness. Although these effects may be useful in certain clinical situations (e.g., preanesthesia), they are not usually desirable concomitants of analgesia, particularly in ambulatory patients. The CNS depressant actions of these drugs can be expected to be at least additive with the sedative and respiratory depressant effects of sedative-hypnotics such as alcohol, barbiturates, and benzodiazepines.

Although it has been suggested that methadone produces more sedation than morphine, this has not been supported by single-dose controlled trials or surveys in hospitalized patients. ${ }^{3}$ However, the half-life of methadone is substantially longer than morphine and can result in cumulative CNS depression after repeated doses. A reduction in dose and interval so that a lower dose is given more frequently may counteract excessive sedation. In addition, other CNS depressants including sedative-hypnotics and antianxiety agents that potentiate the sedative effects of opioids should be discontinued. Concurrent administration of dextroamphetamine in $2.5-\mathrm{mg}$ to $5.0-\mathrm{mg}$ oral doses twice daily has been reported to reduce the sedative effects of opioids. Tolerance usually develops to the sedative effects of opioid analgesics within the first several days of long-term administration.

\section{Constipation}

The most common adverse effect of the opioid analgesics is constipation. These drugs act at multiple sites in the gastrointestinal tract and spinal cord to produce a decrease in intestinal secretions and peristalsis, resulting in a dry stool and constipation. Tolerance develops very slowly to the smooth muscle effects of opioids so that constipation will persist when these drugs are used for chronic pain. At the same time that the use of opioid analgesics is initiated, provision for a regular bowel regimen, including cathartics and stool softeners, should be instituted to diminish this adverse effect.

\section{Urinary retention}

Because the opioid analgesics increase smooth muscle tone, they can cause bladder spasm and an increase in sphincter tone leading to urinary retention, particularly in the elderly patient. Attention should be directed at this potential side effect and catheterization may be necessary to manage this transient side effect.

\section{Multifocal myoclonus}

At high doses, all of the opioid analgesics can produce multifocal myoclonus. ${ }^{2,3,34}$ This complication is most prominent with the use of repeated administration of large parenteral doses of meperidine (e.g., $250 \mathrm{mg}$ or more per day). As previously discussed, accumulation of normeperidine is responsible for this toxicity.

\section{Immune function}

In vitro assays and animal studies indicate that opioids such as morphine can suppress a number of immunologic variables. ${ }^{1,34}$ However, little information is available on the immunologic effects of continuous opioid treatment in patients with persistent pain. Palm et al..$^{35}$ evaluated cellular and humoral immune variables in 10 pain patients (7 chronic noncancer and 3 cancer patients) together with 8 healthy, aged-matched (untreated) controls. 
The patients were studied before and at 1,4 , and 12 weeks during which they received oral sustained-release morphine for pain. Morphine treatment did not affect cellular immune function. Interestingly, these chronic pain patients produced smaller amounts of immunoglobulin than controls, and immunoglobulin production was reduced further by morphine. Additional studies of the immunologic effects of opioids in acute and chronic pain patients are required to determine the clinical significance of the effects observed on humoral immune function by pain itself and the use of opioids to relieve pain.

Interactions between immune cell-derived opioid peptides and opioid receptors located in the peripheral inflamed tissues can result in analgesia. Opioid receptors are present on peripheral sensory nerves and are upregulated during the development of inflammation. Opioid peptides are synthesized in circulating immune cells that migrate to sites of injury. Under stressful stimuli or in response to releasing agents (corticotropin releasing factor or cytokines), these immunocytes can secrete endogenous opioids that activate peripheral opioid receptors by inhibiting either the excitability of sensory nerves or the release of proinflammatory neuropeptides. ${ }^{36}$ This information provides the basis for the development of opioids whose actions are confined to the periphery.

\section{THE OPIOID-TOLERANT PATIENT}

Tolerance develops when a given dose of an opioid produces a decreasing effect, or when a larger dose is required to maintain the original effect. Some degree of tolerance to analgesia appears to develop in most patients receiving long-term opioid analgesic therapy. ${ }^{37}$ The hallmark of the development of tolerance is the patient's complaint of a decrease in the duration of effective analgesia. For reasons not yet understood the rate of development of tolerance varies greatly among cancer patients, so that some will demonstrate tolerance within days of initiating opioid therapy whereas others will remain well controlled for many months on the same dose. ${ }^{38}$ A sudden dramatic increase in opioid requirements may represent a progression of the disease, rather than the development of tolerance per se. In these patients objective evidence of progression of disease is sought and pain management techniques are reevaluated accordingly. ${ }^{38}$ With the development of tolerance, increasing the frequency and/or dose of the opioid are required to provide continued pain relief. Since the analgesic effect is a logarithmic function of the dose of opioid, a doubling of the dose may be required to restore full analgesia. There appears to be no limit to the development of tolerance, and with appropriate dose adjustment, patients can continue to obtain pain relief.
Combinations of opioids with nonopioids that enhance analgesia not only provide additive analgesia, but since tolerance does not develop to the nonopioid component of the mixture, the overall result is a slower rate of development of tolerance. From the start, a nonopioid (e.g., acetaminophen) should be used with the opioid. In the tolerant patient, methotrimeprazine, a nonopioid analgesic, can be substituted for part of the opioid analgesic requirement. Cross-tolerance among the opioid analgesics appears not to be complete, and therefore advantage is gained by opioid rotation and selecting some fraction $(1 / 10-1 / 2)$ of the predicted equianalgesic dose from Table 1 as the starting dose. ${ }^{32}$ The use of bolus or continuous epidural local anesthetics in patients with localized pain (e.g., perineal pain) can dramatically reduce the need for systemic opioids and thus reverse opioid tolerance.

\section{THE OPIOID-DEPENDENT PATIENT: DEFINITIONS AND MISCONCEPTIONS}

\section{Psychological and physical dependence}

The properties of the opioid analgesics that are most likely to lead to misuse or patient mistreatment are effects mediated in the CNS and seen following long-term administration, including psychological dependence and physical dependence. It must be emphasized that while the development of physical dependence and tolerance are predictable pharmacologic effects seen in humans and laboratory animals in response to repeated administration of an opioid, these effects are distinct from the behavioral pattern seen in some individuals and described by the terms psychological dependence or addiction. ${ }^{39}$ Psychological dependence is used to describe a pattern of drug use characterized by a continued craving for an opioid that is manifested as compulsive drugseeking behavior leading to an overwhelming involvement with the use and procurement of the drug. Within these definitions, most but not all individuals who are addicted to opioids will have acquired some degree of physical dependence. However, the converse is not true, and an individual can be physically dependent on an opioid analgesic without being addicted to it. Fear of addiction is a major concern limiting the use of appropriate doses of opioids in hospitalized patients who are in pain. Some patients are reluctant to take even small doses of opioids for fear of becoming addicted. Surveys in hospitalized medical patients ${ }^{40}$ and in burn patients, ${ }^{41}$ and an analysis of the recent medical use and abuse of opioid analgesics, ${ }^{42}$ suggest that medical use of opioids rarely, if ever, leads to drug abuse or iatrogenic opioid addiction. This survey found that from 1990 to 1996 there were significant increases in the medical use of morphine $(59 \%)$, fentanyl $(1,168 \%)$, oxycodone $(23 \%)$, 
and hydromorphone (19\%) without a significant increase in reports of drug abuse (mentions of drug abuse) as compiled by the Drug Abuse Warning Network. ${ }^{42}$ This survey was completed prior to the recent increase in reports of the abuse of Oxycontin. ${ }^{43}$

Physical dependence is the term used to describe the phenomenon of withdrawal when an opioid is abruptly discontinued or if an opioid antagonist is administered. The severity of withdrawal is a function of the dose and duration of administration of the discontinued opioid (i.e., the patient's prior opioid exposure). The administration of an opioid antagonist to a physically dependent individual produces an immediate precipitation of the withdrawal syndrome. Patients who have received repeated doses of a morphinelike agonist to the point where they are physically dependent may experience an opioid withdrawal reaction when given a mixed agonistantagonist. Prior exposure to a morphinelike drug can greatly increase a patient's sensitivity to the antagonist component of a mixed agonist-antagonist. Therefore, when used for chronic pain, the mixed agonist-antagonist opioids should be tried prior to initiating prolonged administration of a morphinelike agonist.

The abrupt discontinuation of an opioid analgesic in a patient with significant prior opioid experience will result in signs and symptoms characteristic of the opioid withdrawal or abstinence syndrome. The onset of withdrawal is characterized by the patient's report of feelings of anxiety, nervousness and irritability, and alternating chills and hot flushes. A prominent withdrawal sign is "wetness" including salivation, lacrimation, rhinorrhea and diaphoresis, as well as gooseflesh. ${ }^{39}$ At the peak intensity of withdrawal, patients may experience nausea, vomiting, abdominal cramps, insomnia and, rarely, multifocal myoclonus. The time course of the withdrawal syndrome is a function of the elimination half-life of the opioid to which the patient has become dependent. Abstinence symptoms will appear within 6 to 12 hours and reach a peak at 24 to 72 hours following cessation of a short half-life drug such as morphine, whereas onset may be delayed for 36 to 48 hours with methadone, a long half-life drug. Therefore, it is important to emphasize that even in a patient in whom pain has been completely relieved by a procedure (e.g., a cordotomy), it is necessary to slowly decrement the opioid dose to prevent withdrawal. ${ }^{2,3}$ Experience indicates that the usual daily dose required to prevent withdrawal is equal to approximately one fourth of the previous daily dose. This dose, called for want of a better term the detoxification dose, is given in four divided doses. The initial detoxification dose, is given for 2 days and then decremented by one half (administered in four divided doses) for 2 days until a total daily dose of 10 to $15 \mathrm{mg}$ per day (in morphine equiva- lents) is reached; after 2 days on this dose, the opioid can be discontinued. Thus, a patient who had been receiving $240 \mathrm{mg}$ per day of morphine for pain would require an initial detoxification dose of $60 \mathrm{mg}$ given as $15 \mathrm{mg}$ every 6 hours. Alternately, the patient may be switched to the equieffective oral analgesic dose of methadone, using one fourth of this dose as the initial detoxification dose and proceeding as described previously. ${ }^{2-4}$

\section{CONCLUSIONS}

The fundamental concept that underlies the appropriate and successful management of pain by the use of opioid and nonopioid analgesics is individualization of analgesic therapy. ${ }^{4,5}$ This concept entails an understanding of the clinical pharmacology of the opioids to provide the information necessary for the selection of the right analgesic, administered in the right dose and on the right schedule so as to maximize pain relief and minimize adverse effects. ${ }^{4-6}$ This comprehensive approach begins with the nonopioids or mild analgesics for mild pain. In patients with moderate pain that is not controlled by nonopioids alone, the so-called weak opioids alone or in combination should be prescribed. In patients with severe pain, a strong opioid is the drug of choice given alone or in combination. At all levels certain adjuvant drugs are used for specific indications. ${ }^{5-7}$ The analgesic efficacy of the opioids does not appear to have a conventional dose-related ceiling, rather dose escalation is usually limited by the incidence and severity of adverse effects. Therefore, individual titration of the dose combined with measures to reduce the adverse effects is key to optimizing the management of pain with these drugs.

\section{REFERENCES}

1. Gutstein HB, Akil H. Opioid analgesics. In: Hardman JG, Limbird LL, eds. Goodman \& Gilman's the pharmacological basis of therapeutics, 10th ed. McGraw-Hill, 2001:569-619.

2. Inturrisi CE, Hanks GWC. Opioid analgesic therapy. In: Doyle D, Hanks GWC, Macdonald N, eds. Oxford textbook of palliative medicine. Oxford University Press, 1993:166-82.

3. Foley KM. Problems of overarching importance, which transcend organ systems. In: Bennett JC, Plum F, eds. Cecil textbook of medicine. Philadelphia: Saunders, 1996:100-7.

4. Principles of analgesic use in the treatment of acute pain and cancer pain, 4th ed. American Pain Society, 1999.

5. Jacox A, Carr DB, Payne R, et al. Management of cancer pain. Clinical Practice Guideline No. 9. AHCPR Publication No. 940592. Rockville, MD: Agency for Health Care Policy and Research, US Department of Health and Human Services, Public Health Service, March 1994.

6. Cancer pain relief. Geneva: World Health Organization, 1986.

7. Portenoy RK. Adjuvant analgesic agents. Hematol Oncol Clin North Am 1996;10:103-19.

8. Nestler EJ, Molecular neurobiology of addiction. Am J Addict 2001;10:201-17.

9. Kieffer BL. Opioids: first lessons from knockout mice. Trends Pharmacol Sci 1999;20:19-26. 
10. Terman G, Bonica JJ. Spinal mechanisms and their modulation. In: Loeser J, ed. Bonica's management of pain, 3rd ed. Lippincott Williams \& Wilkins, 2001:73-152.

11. Portenoy RK, Thaler HT, Inturrisi CE, et al. The metabolite morphine-6-glucuronide contributes to the analgesia produced by morphine infusion in patients with pain and normal renal function. Clin Pharmacol Ther 1992;51:422-31.

12. Rossi GC, Brown GP, Leventhal L, et al. Novel receptor mechanisms for heroin and morphine-6-glucuronide analgesia. Neurosci Lett 1996;216:1-4.

13. Portenoy RK, Foley KM, Stulman J, et al. Plasma morphine and morphine-6-glucuronide during chronic morphine therapy for cancer pain: plasma profiles, steady-state concentrations and the consequences of renal failure. Pain 1991;47:13-9.

14. Tiseo PJ, Thaler HT, Lapin J, et al. Morphine-6-glucuronide concentrations and opioid-related side effects: a survey in cancer patients. Pain 1995;61:47-54.

15. Mercadante $\mathrm{S}$. The role of morphine glucuronides in cancer pain. Palliat Med 1999;13:95-104.

16. Smith MT. Neuroexcitatory effects of morphine and hydromorphone: evidence implicating the 3-glucuronide metabolites. Clin Exp Pharmacol Physiol 2000;27:524-8.

17. Ripamonti C, Groff L, Brunelli C, et al. Switching from morphine to oral methadone in treating cancer pain: what is the equianalgesic dose ratio? J Clin Oncol 1998;16:3216-21.

18. Foley KM, Houde RW. Methadone in cancer pain management: individualize dose and titrate to effect. J Clin Oncol 1998;16: 3213-5.

19. Morley JS. New perspectives in our use of opioids. Pain Forum $1999 ; 8: 200-5$

20. Inturrisi CE. Old dogs, new tricks. Pain Forum 1999;8:210-2.

21. Davis AM, Inturrisi CE. d-Methadone blocks morphine tolerance and $N$-methyl-D-aspartate (NMDA)-induced hyperalgesia. J Pharmacol Exp Ther 1999;289:1048-53.

22. Inturrisi CE. Preclinical evidence for a role of glutamatergic systems in opioid tolerance and dependence. Sem Neurosci 1997;9: 110-9.

23. Bennett GJ. Update on the neurophysiology of pain transmission and modulation: focus on the NMDA-receptor. J Pain Symptom Manage 2000;19:S2-6.

24. Sang CN. NMDA-receptor antagonists in neuropathic pain: experimental methods to clinical trials. J Pain Symptom Manage 2000; 9:S21-5.

25. Caruso FS. MorphiDex pharmacokinetic studies and single-dose analgesic efficacy studies in patients with postoperative pain. $J$ Pain Symptom Manage 2000;19:S31-6.
26. Jasinski DR. Abuse potential of morphine/dextromethorphan combinations. J Pain Symptom Manage 2000;19:S26-30.

27. Katz NP. MorphiDex (MS:DM) double-blind, multiple-dose studies in chronic pain patients. J Pain Symptom Manage 2000;19: S37-41

28. Gear RW, Miaskowski C, Gordon NC, et al. Kappa-opioids produce significantly greater analgesia in women than in men. Nat Med 1996;11:1248-50.

29. Gear RW, Gordon NC, Heller PS, et al. Gender difference in analgesic response to the kappa-opioid pentazocine. Neurosci Lett 1996;205:207-9.

30. Gal TJ. Naloxone reversal of buprenorphine-induced respiratory depression. Clin Pharmacol Ther 1989;45:66-71.

31. Noemi D, de Stoutz MD, Bruera E, et al. Opioid rotation for toxicity reduction in terminal cancer patients. J Pain Symptom Manage 1995;10:378-84

32. Anderson R, Saiers JH, Abram S, et al. Accuracy in equianalgesic dosing: Conversion dilemmas. J Pain Symptom Manage 2001;21: 397-406.

33. Tyndale RF, Droll KP, Sellers EM. Genetically deficient CYP2D6 metabolism provides protection against oral opiate dependence. Pharmacogenetics 1997;7:375-9.

34. Bruera E, Pereira J. Neuropsychiatric toxicity of opioids. In: Jensen TS, Turner JA, Wiesenfeld-Hallin Z, eds. Proceedings of the 8th World Congress on Pain, vol 8. Seattle: IASP Press, 1997:717-38.

35. Palm S, Lehzen S, Mignat C, et al. Does prolonged oral treatment with sustained-release morphine tablets influence immune function? Anesth Analg 1998;86:166-72.

36. Machelska H, Stein C. Pain control by immune-derived opioids. Clin Exp Pharmacol Physiol 2000;27:533-6.

37. McQuay H. Opioids and pain management. Lancet 1999;353: 2229-32.

38. Kanner RM, Foley KM. Patterns of narcotic drug use in a cancer pain clinic. Ann NY Acad Sci 1981;362:161-72.

39. O'Brien. Drug addiction and drug abuse. In: Hardman JG, Limbird LL, eds. Goodman \& Gilman's the pharmacological basis of therapeutics, 10th ed. McGraw-Hill, 2001:621-42.

40. Porter J, Jick H. Addiction rare in patients treated with narcotics. N Engl J Med 1980;302:123.

41. Perry S, Heidrich G. Management of pain during debridement: a survey of U.S. burn units. Pain 1982;13:267-80.

42. Joranson DE, Ryan KM, Gilson AM, Dahl JL. Trends in medical use and abuse of opioid analgesics. JAMA 2000;283:1710-4.

43. Passik SD. Responding rationally to recent reports of abuse/diversion of Oxycontin. J Pain Symptom Manage 2001;21: $359-60$ 